\title{
Crop Water Stress Index is a Sensitive Water Stress Indicator in Pistachio Trees
}

Testi, L. ${ }^{\left({ }^{(*)}\right.}$, Goldhamer D.A. ${ }^{(b)}$, Iniesta, F. ${ }^{(a)}$, Salinas M. ${ }^{(b)}$

a) Instituto de Agricultura Sostenible, CSIC, Apdo. 4084, 14080 Córdoba, Spain

b) University of California, Kearney Agricultural Center, Dept. Land Air \& Water Resources, 9240 S. Riverbend Ave., Parlier, CA 93648, USA

\section{Corresponding author:}

Luca Testi

Instituto de Agricultura Sostenible, CSIC - Apdo. 4084, 14080 Córdoba, Spain.

Tel: +34957499231; Fax: +34957499252

Running Title: Crop Water Stress Index as a Stress Indicator in Pistachio

Keywords: Canopy Temperature, Water Stress, Regulated Deficit Irrigation, Remote Sensing, Thermal Image 


\section{Abstract}

Regulated Deficit Irrigation (RDI) strategies, often applied in tree crops, require precise monitoring methods of water stress. The Crop Water Stress Index (CWSI), based on canopy temperature measurements, has shown to be an good indicator of water deficits in field crops but has seldom been used in trees. The CWSI was measured on a continuous basis in a Central California mature pistachio orchard, under full and deficit irrigation. Two treatments - control, returning the full evapotranspiration $\left(\mathrm{ET}_{\mathrm{c}}\right)$ and RDI, irrigated with $40 \% \mathrm{ET}_{\mathrm{c}}$ during the Stage two of fruit grow (shell hardening). During Stage two, the canopy temperature - measured continuously with infrared thermometers - of the RDI treatment was consistently higher than the control during the hours of active transpiration; the difference decreasing after irrigation. The Non-Water-Stressed Baseline (NWSB), obtained from clear-sky days canopy-air temperature differential and vapour pressure deficit (VPD) in the control treatment, showed a marked diurnal variation in the intercept, mainly explained by the variation in solar radiation. By contrast, the NWSB slope remained practically constant along the day. Diurnal evolution of calculated CWSI was stable and near zero in the control, but showed a clear rising diurnal trend in the RDI treatment, increasing as water stress increased around midday. The seasonal evolution of the CWSI detected large treatment differences throughout the RDI stress period. While the CWSI in the well-irrigated treatment rarely exceeded 0.2 troughout the season, in the RDI it reached values of 0.8-0.9 near the end of the stress period. The CWSI responded to irrigation events along the whole season, and detected clearly mild water stress, suggesting extreme sensitivity to variations in tree water status. It correlated well with mid-day leaf water potential (LWP), but was more sensitive than LWP at mild stress levels. We conclude that the CWSI, obtained from continuous nadir-view measurements with infrared thermometers, is a good and very sensitive indicator of water stress in pistachio. We recommend the use of canopy temperature measurements taken from 1200 to $1500 \mathrm{~h}$, together with the following equation for the NWSB: $\left(T_{c}-T_{a}\right)=-1.33 \cdot V P D+2.44$. Measurements of canopy temperature with VPD $<2 \mathrm{kPa}$ are likely to generate significant errors in the CWSI calculation and should be avoided. 


\section{Introduction}

2 The relation between plant canopy temperature and transpiration through the effect of

3 the transpirational cooling is well known (e.g. Eaton and Belden 1929; Ehrler 1973;

4 Gates 1964; Wallace and Clum 1938), but practical application of this concept came

5 only with the availability of the infra-red thermometer, or IRT (Monteith and Szeicz

6 1962; Tanner 1963). The temperature of a canopy $\left(T_{c}\right)$ deviates from air temperature

$7 \quad\left(T_{a}\right)$, in a way that is, ceteris paribus, strictly dependent on the rate of transpiration.

8 Whenever water is evaporated from a leaf, the latent heat of evaporation is drawn

9 from the leaf, cooling it down. Plants reduce their transpiration rate as water in the

10 soil becomes less available by closing the stomata. Stomatal conductance is thus the

11 physiological parameter that affects canopy temperature: a water-stressed canopy is

12 hotter than a well watered one under the same environmental conditions. Soon after a

13 portable infrared thermometer was developed, it became clear that water stress could

14 be quantified through canopy temperature reading (Jackson et al. 1977). The problem

15 was how to normalise the canopy temperature in a way that the stomatal

16 (physiological) effect on the canopy heat balance could be separated from the physical

17 ones (radiation, convection, vapour pressure, etc). In 1981 an applicable stress index

18 was formulated - the crop water stress index (CWSI) - based on canopy-air

19 temperature difference $\left(T_{c}-T_{a}\right)$ (Idso et al. 1981). If one can obtain the two limits of $T_{c}$

20 for potential and null transpiration of a crop (or, similarly, for maximum and

21 minimum canopy conductance) under given environmental conditions, then the CWSI

22 can be calculated as follows (Idso et al. 1981):

23

$24 \quad \mathrm{CWSI}=\frac{\left(T_{c}-T_{a}\right)-\left(T_{c}-T_{a}\right)_{L L}}{\left(T_{c}-T_{a}\right)_{U L}-\left(T_{c}-T_{a}\right)_{L L}}$ 
1 where $\left(T_{c^{-}} T_{a}\right)$ is the measured foliage-air temperature differential, $\left(T_{c}-T_{a}\right)_{\mathrm{LL}}$ is the

2 expected lower limit of $\left(T_{c}-T_{a}\right)$ in the case of a canopy that is transpiring at the

3 potential rate, and $\left(T_{c}-T_{a}\right)_{\mathrm{UL}}$ is the expected differential in case of a non-transpiring

4 canopy. The lower and upper limits of $T_{c}-T_{a}$ used in Eq 1 can be obtained using three

5 conceptually different methods.

6 The first was proposed by Idso et al. (1981) who found that, under good soil water

7 conditions (ideally maximum stomatal conductance), $T_{c}-T_{a}$ is a linear function of VPD

8 (non-water-stressed baseline, NWSB). Once the NWSB is empirically obtained, $\left(T_{c^{-}}\right.$

$\left.9 T_{a}\right)_{\mathrm{LL}}$ is calculated at any given time solving the baseline equation for the actual VPD.

10 The upper limit $\left(T_{c}-T_{a}\right)_{\mathrm{UL}}$ is a constant. It is found solving the same NWSB equation

11 for a hypothetical slightly negative VPD, that represents the vapour pressure 12 difference generated by the temperature differential $\left(T_{c}-T_{a}\right)$ when VPD=0 (Idso et al.

13 1981). The upper limit value is expected to be close to the intercept $a$ of the NWSB

14 (depending on temperature) and is equal to $a$ only in the special case that $a=0$. This

15 method is simple, but requires a specific experiment, and is site-dependent. Idso

16 (1984) found the baselines for many species to be independent of temperature,

17 radiation, and wind speed, when the measurements were taken from 3 hours after

18 sunrise to 3 hours before sunset. However, others disputed this argument (e.g.

19 Gardner et al. 1992; Nielsen 1994).

20 The second approach for obtaining the upper and lower bounds of $\left(T_{c}-T_{a}\right)$ is 21 theoretical, as formulated by Jackson et al. (1981), shortly after Idso's (1981) method.

22 Jackson expressed $\left(T_{c}-T_{a}\right)$ combining energy balance and diffusion equations: the

23 bounds are found by forcing the stomatal resistance $\rightarrow \infty$ or setting it to zero for $\left(T_{c^{-}}\right.$

$\left.24 T_{a}\right)_{\mathrm{UL}}$ or $\left(T_{c}-T_{a}\right)_{\mathrm{LL}}$ respectively. This method requires knowledge of variables which

25 are difficult to obtain (like net radiation and, in particular, aerodynamic resistance). 
1 The last approach proposed to obtain the bounds of $\left(T_{c^{-}} T_{a}\right)$ makes use of direct

2 measurements over wet or dry reference surfaces, either natural or artificial.

3 Experiences were successfully carried on with dry leaves replicas (Qiu et al. 1996;

4 Wang et al. 2005) or petroleum-jelly-sprayed leaves (Jones 1999b) for obtaining $\left(T_{c^{-}}\right.$

$\left.5 T_{a}\right)_{\mathrm{UL}}$, while wet panels (Cohen et al. 2005; Jones et al. 2002; Moller et al. 2007) or

6 wetted leaves or canopy portions (Jones 1999a; b; Jones et al. 2002) were used as

7 reference for $\left(T_{c}-T_{a}\right)_{\mathrm{LL}}$. The design and placement of reference surfaces is paramount

8 to mimic precisely the heat balance of the canopy, and they are difficult to maintain.

9 This method has great scientific potential, but few chances, at present, to be used 10 directly and continuously for irrigation scheduling.

11 A general problem often encountered in assessing plant water stress by canopy 12 temperature is the representativeness of the target area. The inclusion of non13 transpiring surfaces (like soil, branches etc.) inside the IRT field of view generate 14 unwanted shifts in the temperature readings, thus decreasing the precision of $T_{c}$ 15 measurements (Hatfield et al. 1985; Wanjura et al. 1984). This problem often arises 16 under incomplete cover, and was partially overcome by using spectral vegetation 17 indexes (Moran et al. 1994) or narrow-angle IRT sensors (Jones 1999a). At present, 18 affordable and portable thermal imaging devices with high resolution are available; 19 this has solved the problem of discriminating between foliage and non-transpiring 20 surfaces. The thermal images (alone or with the aid of visible Red-Green-Blue 21 images) can now be stripped of the unwanted non-leaf components, and the inclusion 22 of reference surfaces in the camera image can aid this process (Jones et al. 2002; 23 Moller et al. 2007). Another advantage of thermal imaging over classic IRT 24 thermometry is that it allows to distinguish among temperatures of specific parts of 
1 the plant, like sunny or shaded leaves or vegetative organs, and to obtain canopy

2 temperature variability indices, that are also related to water stress (Fuchs 1990).

3 Nevertheless, at present, thermal imaging poses the same practical problem previously

4 mentioned for the reference surfaces normalisation method: they are not suitable for

5 continuous operation. Thermal cameras are still too costly and delicate to be deployed

6 unattended in the field, and complex image processing is not easy to automate, while

7 satellite thermal imagery still don't have the necessary resolution to discern organs of

8 the size of a leaf.

9 The CWSI concept, mainly normalized with Idso's empirical approach, has been 10 applied mostly to annual crops (Abduljabbar et al. 1985; Idso 1982; Nakayama and 11 Bucks 1983; Wanjura et al. 1990; Yazar et al. 1999). It has been used less with tree 12 crops, presumably because their incomplete cover hinder obtaining accurate 13 temperature readings of the transpiring canopy parts. Idso (1982) included only one 14 tree species (fig) in his group of $T_{c}-T_{a}$ baselines. Other works appeared on peach 15 (Glenn et al. 1989), nectarines (Tormann 1986), pecan (Garrot et al. 1993), apple 16 (Andrews et al. 1992), and sweet lime (Sepaskhah and Kashefipour 1994).

17 One of the limitations of the CWSI is that its precision is climate-dependent. At low 18 VPDs, the distance between the upper and lower bound temperatures is smaller, while 19 the measurements errors have the same magnitude. The signal-noise ratio is thus 20 worse (Jones 2004), to the point that it is not advisable to use it in very humid 21 climates or when the variability of VPD and radiation is high. In such climates, 22 obtaining the canopy temperature from specific leaves (with termal imaging) and 23 normalising the CWSI with the aid of reference surfaces can greatly improve the 24 CWSI precision (Jones 1999a; Jones et al. 1997). 
1 The use of regulated deficit irrigation (RDI) in orchards (Boland et al. 1993; Chalmers

2 et al. 1986) calls for a precise tool to monitor water stress (Goldhamer et al. 1999). In

3 addition to the traditional water stress indicators used in trees, for instance soil water

4 content, leaf water potential or leaf conductance, there are newer methods, such as

5 trunk diameter fluctuations and sap flow, that provide continuous automatic records.

6 The traditional soil and plant based monitoring is time consuming and provides point

7 measurements; a single location of soil, a leaf, branch, or tree. They are incapable of

8 representing the water status of an entire orchard without being financially impractical

9 due to the number of monitoring sites required. Today IRTs are relatively cheap,

10 rugged, precise and easily automated. The use of the CWSI from simple IRTs

11 continuous measurements, normalised with the empirical approach, could be a simple,

12 cost-effective method to monitor the water stress and schedule irrigations under RDI

13 strategies in tree crops, provided that:

14 1) The IRTs can be positioned in a way that they see only tree foliage. Furthermore, if 15 the frequency of differently illuminated leaves in the canopy portion viewed by the

16 IRTs at the time of measurement is constant enough, then the effect of shaded leaves 17 on the average canopy temperature can be accounted for in the baseline 18 parameterisation.

19 2) The empirical baselines, especially the NWSB, are stable under the environmental 20 conditions expected during the irrigation season. If instability is found, the variation 21 in the baseline should be predictable, thus the errors in CWSI can be minimised. Also, 22 dry, stable weather conditions are desirable to avoid important errors in defining the 23 CWSI.

24 Pistachio orchards (Pistacia vera L.) in central California (one of the world's more 25 important pistachio production areas) are irrigated during dry and stable weather 
1 conditions. The orchards are mostly homogeneous - only one cultivar is used - and

2 they are pruned to have a globular, dense and regular canopy.

3 The main goal of this work was to assess the reliability of CWSI (obtained with

4 continuous measurements of average infra-red canopy temperature and with the

5 empirical normalisation) for detecting water stress in pistachio. We addressed this

6 problem by obtaining the NWSB, assessed the quality and stability of the CWSI of

7 trees subjected to a water stress cycle, and described and explained the sources of

8 variation in the stress indicator. Importantly, we established the relationship between

9 CWSI and leaf water potential, the more commonly accepted indicator of tree water 10 status in this crop.

11 


\section{Materials and methods}

\section{Experimental site}

4 The study was conducted in a commercial pistachio orchard located in Madera

5 County, California, 36 58' 54" N, 119 57' 25" W, 75m elevation, during the 2006

6 season. The soil is classified as sandy loam, of variable depth (maximum about $3 \mathrm{~m}$ ).

$7 \quad$ Pistachio trees of the cv. Kerman (P. integerrima rootstock) were planted in 1994, at a

8 spacing of $5.8 \mathrm{~m} \times 5.2 \mathrm{~m}$ in a triangular grid. At the time of the experiment, the trees

9 were $4.8 \mathrm{~m}$ high, their canopy volume was $37.5 \mathrm{~m}^{3}$ per tree, and they covered $57 \%$ of

10 the ground in vertical projection (average values obtained in 100 trees). The irrigation

11 method is microsprinkler at the same spacing as the trees, with the sprinklers located

12 in the trees rows mid-way between trees. The microsprinklers' nominal factory

13 discharge rate is $93.9 \mathrm{~L} \mathrm{~h}^{-1}$ at 1.38 bars, equivalent to $3.1 \mathrm{~mm} \mathrm{~h}^{-1}$ in the configuration

14 of this experiment and at the same operation pressure.

15 Two large plots of 32 ha each were irrigated with two different irrigation schedules.

16 The first one (Control) was irrigated restoring $100 \%$ of the potential 17 evapotranspiration $\left(\mathrm{ET}_{\mathrm{c}}\right)$ for the whole season. The second treatment (RDI) was 18 irrigated following a regulated deficit irrigation schedule, that provided only $40 \%$ of 19 the crop $\mathrm{ET}_{\mathrm{c}}$ during Stage 2 of fruit growth (Goldhamer and Beede 2004), which takes 20 place during the shell hardening period (19 May to $11 \mathrm{July} 2006$ ), and $100 \%$ of $\mathrm{ET}_{\mathrm{c}}$ 21 during the rest of the irrigation season. The $\mathrm{ET}_{\mathrm{c}}$ for scheduling the irrigations was 22 calculated as $\mathrm{ET}_{\mathrm{c}}=\mathrm{ET}_{0} \cdot \mathrm{K}_{\mathrm{c}}$, where $\mathrm{ET}_{0}$ is the reference evapotranspiration, and $\mathrm{K}_{\mathrm{c}}$ is 23 the pistachio crop coefficient under unstressed conditions (Goldhamer 2005), given in 24 Table 1. The $\mathrm{ET}_{0}$ and the other relevant meteorological variables were obtained from 25 the nearest meteorological station (Madera, station \#145 of the California Irrigation 
1 Management Information System network), located about $10 \mathrm{~km}$ away from the

2 experimental site. Irrigation was applied weekly, although management and labour

3 constraints occasionally induced small variations in the watering frequency.

5 Canopy temperature measurements and CWSI

6 Four infrared thermometers (model IRR-P, Precision Infra-Red Radiometer, Apogee 7 Instruments Inc. Logan, UT) were mounted over four average-size trees in each 8 treatment. The sensors angular field of view is $44^{\circ}$, and the absolute accuracy under 9 the experimental conditions was $0.2^{\circ} \mathrm{C}$ (manufacturer's specifications). The mounting 10 consisted of an aluminium mast with an horizontal mounting arm, ending with a white 11 PVC case protecting the sensor, that was directed aiming vertically downward (nadir 12 view) and targeting the center of the canopy from a distance of approximately one 13 meter (Fig. 1). A similar instrumental set-up was used by Sepulcre-Canto' et al (2006). 14 With this setting, the infrared thermometers (henceforth IRTs) were viewing 15 approximately $0.5 \mathrm{~m}^{2}$ of foliage in the canopy top. Leaves were estimated by visual 16 inspection to occupy at least the $90-95 \%$ of the IRTs field of view.

17 All the IRTs were connected to a datalogger (model CR10X, Campbell Scientific, 18 Logan UT), that recorded canopy temperatures every minute and stored the 5-min 19 averages. The canopy temperature measurements started on 13 June 2006 (DOY 164) 20 and continued without interruption until 21 September (DOY 264).

21 The Crop Water Stress Index was calculated continuously, using Eq. 1. $T_{a}$ and VPD 22 were obtained from the weather station. The NWSBs were derived by linear 23 regression of the values of $\left(T_{c}-T_{a}\right)$ measured in the Control plot versus VPD, for a 24 given time of the day; the upper limit $\left(T_{c}-T_{a}\right)_{U L}$ was obtained solving the NWSB 
1 equation for $\mathrm{VPD}=0$ then correcting for the difference in vapor pressure induced by

2 the difference in temperature $T_{c}-T_{a}$ (Idso et al. 1981).

\section{$4 \quad$ Leaf water potential}

5 Measurements of midday shaded leaf water potential $(\Psi)$ were obtained in the 6 experimental trees every 5-6 days. Midday shaded leaf water potential was found to 7 be highly correlated with stem water potential in almonds (Goldhamer and Fereres 8 2001) and is easier to take since covering the leaves with small bags for a given

9 amount of time is not necessary. Four leaves, taken from inside the canopy as close to 10 the trunk as possible, were cut from each tree around $1200 \mathrm{~h}$ and put in a pressure 11 chamber (model 3005, Soilmoisture Equipment Co., Santa Barbara, CA) immediately 12 after cutting. The leaves were handled with a damp cloth, and the rate of pressure 13 increase in the chamber was relatively slow to avoid reading errors (Hsiao 1990; 14 Turner and Long 1980).

\section{Results and discussion}

18 The nadir-view radiometric temperature of the canopy (henceforth $T_{c}$ ) showed little

19 variation among trees. About $80 \%$ of our $T_{c}$ measurements (5-min averages of 1 -min 20 measurements) showed a coefficient of variation $\mathrm{C}_{\mathrm{v}}$ (the ratio of the standard 21 deviation to the mean) of less than $2 \% ; 99.6 \%$ of the measurements had $\mathrm{C}_{\mathrm{v}}<5 \%$. This 22 suggests that: a) the observed trees were in similar water status; and b) that the canopy 23 surface viewed by the sensor (or the number of leaves falling inside the sensor field of 24 view) was big enough to remove the variability due to the leaves' orientation with 
1 respect to the sun angle. Thus, we are reasonably confident in the representativeness

2 of the mean.

3 The two treatments showed clear differences in $T_{c}$ during the RDI timeframe. This can

4 be appreciated in Fig. 2, showing the time series of $T_{c}$ (on the left side) and $T_{c}-T_{a}$ (on

5 the right) during three days that differed in tree water status. The first comparison is

6 for 18 June (DOY 169), when the Control treatment had been irrigated with the full 7 crop water requirement and the RDI had been subjected to a month of deficit 8 irrigation with the last irrigation event on 9 June (Fig. 2a and Fig. 2d). Immediately 9 after sunrise, the canopy of the RDI warmed up faster than the Control, exceeding the 10 Control $T_{c}$ by about $6{ }^{\circ} \mathrm{C}$ at about $1500 \mathrm{~h}$ (Fig. 2a). The temperature of the RDI 11 canopies was higher than the air temperature from midday to $1700 \mathrm{~h}$ (Fig. 2D), and a 12 consistent difference in $T_{c}-T_{a}$ between the two treatments was apparent until well after 13 sunset. This behaviour in $T_{c}$ and $T_{c}-T_{a}$ is symptomatic of reduced transpiration due to 14 water stress. The effect of irrigation over the thermal conditions of the canopy is 15 shown in Fig. $2 b$ and Fig. 2e, presenting data from 19 June (DOY 170), when an 16 irrigation was applied to RDI in the early morning. The thermal behaviour is similar 17 to the previous day, but the differences between treatments were greatly attenuated; 18 the maximum difference in $T_{c}$ between the Control and RDI is now only around $2{ }^{\circ} \mathrm{C}$ 19 (Fig. 2b), and the RDI canopy temperature barely exceeds air temperature (Fig. 2e). 20 The RDI trees had better water status than the previous day and an apparent increase 21 in transpiration. Nevertheless, the RDI trees had not fully recovered. By 15 August 22 (DOY 227, Fig. 2c and Fig. 2f) the imposition of stress in the RDI treatment had 23 ended more than a month before (11 July) and subsequently, both the Control and 24 RDI regimes had the same amount of applied water; enough to avoid reducing 25 transpiration below the potential rate. Differences in canopy thermal behaviour 
1 between the treatments are very small, suggesting that the RDI trees had mostly

2 recovered from the stress period (Fig. 2c and Fig. 2f). The minimum and maximum

$31300 \mathrm{~h}$ averages of $T_{c}-T_{a}$ registered during this experiment were, respectively, $-5.1^{\circ} \mathrm{C}$

4 (Control on 24 July) and $3.10^{\circ} \mathrm{C}$ (RDI on 10 July, 1 day before the end of the RDI

5 stress period). The maximum difference between the canopy temperatures of the two

6 treatments was $7.13{ }^{\circ} \mathrm{C}$, recorded at $1530 \mathrm{~h}$ on 26 June.

\section{Crop Water Stress Index}

9 The first attempt to obtain the non-water-stressed baseline (NWSB) using clear-sky 10 days data from 0900 in the morning to 1700 in the afternoon in the well watered trees,

11 yielded such a large scatter that it was impossible to obtain a reasonably sound $12\left(T_{c}-T_{a}\right)_{L L}$. Upon analysing the stability of the NWSB at different times of the day, we 13 found a marked change in the diurnal NWSB parameters, while the scatter in the plots 14 of $\left(T_{c}-T_{a}\right)$ versus VPD for a given time of the day was small (Fig. 3). This diurnal 15 behaviour of the pistachio NWSB is presented in Fig. 3a (morning) and Fig. 3b 16 (afternoon). In these plots the hourly values of $\left(T_{c}-T_{a}\right)$ are regressed vs. VPD 17 separately in different hours of the day; each point is obtained from hourly average $T_{c}$, $18 T_{a}$ and VPD in a given day at a given hour, using the $T_{c}$ of the well-watered trees. The 19 slope of the baselines $(b)$ seems rather stable, with the partial exception of the $0900 \mathrm{~h}$ 20 plot, but its slope is not significantly different from the slope of the other hours. By 21 contrast, the intercept $(a)$ is clearly increasing in the morning and decreasing in the 22 afternoon. The parameters of the baseline equations obtained at different times of the 23 day are given in Table 2. An explanation for the shifting of the NWSB is provided by 24 Jackson's theoretical equation for the NWSB (Jackson et al. 1981): 
$1 \quad\left(T_{c}-T_{a}\right)=r_{a} R_{n} \frac{\gamma}{\rho C_{p}(\Delta+\gamma)}-\frac{1}{\Delta+\gamma} V P D$

2 where $\Delta$ is the slope of the saturated vapour pressure vs. temperature, namely $3\left(e_{s c}-e_{s a}\right) /\left(T_{c}-T_{a}\right)$, where $e_{s c}$ and $e_{s a}$ are the saturated vapour pressures at $T_{c}$ and $T_{a}$

4 respectively, $\rho$ is the density of air, $C_{p}$ the heat capacity of air, $r_{a}$ is the aerodynamic

5 resistance to water vapour transfer, and $\gamma$ is the psycrometric constant.. Eq. 2 shows

6 that the intercept is a function of both $r_{a}$ and $R_{n}$, thus is expected to increase with solar

7 radiation and decrease with wind speed. Such behaviour was predicted theoretically

8 by Hipps et al. (1985), and supported by some measurements, but has never been

9 confirmed in trees.

10 Our infrared thermometers were arranged for nadir-view, so they targeted a relatively

11 horizontal foliage surface at the top of the canopy. As the trees were quite uniform in

12 height, there was no shading from the neighboring trees, and the radiation incident

13 over the canopy portion enclosed in the IRT field of view, in a clear-sky day, should

14 be closely related to the solar angle by the cosine law. The shift in the NWSB during

15 the day (Fig. 4) is mainly explained by the zenith solar angle, that probably acts on the

16 IRT targeted canopy area not only by changing the total amount of radiation, but also

17 - depending on canopy roughness - the fraction of shaded leaves on the total seen by

18 the sensor.

19 In practical terms, there is little need to account for the shifting baseline if one uses 20 measurements of $T_{c}$ and $T_{a}$ taken from $1200 \mathrm{~h}$ to $1500 \mathrm{~h}$. The parameters of the 21 equation of the NWSB obtained with the measurements in this period of the day are 22 also given in Table 2; the line for $1200 \mathrm{~h}$ to $1500 \mathrm{~h}$ is shown (dashed bold) in Fig. $3 \mathrm{~b}$.

23 Changes in the aerodynamic conductance due to wind speed seem to have a less 24 important effect than solar radiation on the NWSB, in the aerodynamic conditions of 
1 the experiment: Fig. 5 shows the values of $\left(T_{c}-T_{a}\right)$ vs. VPD at $1500 \mathrm{~h}$, but

2 disaggregated in three arbitrarily chosen wind speed classes. Wind speed seems to

3 have some effect on the slope of the baseline, but statistically the three regression

4 lines are the same as the $1500 \mathrm{~h}$ regression obtained including all wind speeds (Fig.

$53 \mathrm{~b}$ ), which equation is given in Table 2. Although the analysis is limited in range (the

6 experimental area is not particularly windy), we can assume that under similar wind

7 speeds (and with trees of similar size) the variation in the aerodynamic conductance

8 has a negligible effect on the NWSB.

9 The variation of the NWSB poses the question of how the resulting CWSI changes

10 when it is determined at different times of the day. The daily evolution of the CWSI in

11 the two treatments on 3 July is shown in Fig. 6, calculated from air and canopy 12 temperature readings at 10-min intervals and varying the NWSB as presented in Table

13 2. On that day, the RDI trees were near the end of the deficit irrigation period and thus

14 quite stressed, as evidenced by the leaf water potential data also shown in Fig. 6.

15 While the CWSI of the Control trees is stable and near zero throughout the day, the

16 CWSI of the RDI trees increases steadily and near-linearly until around $1330 \mathrm{~h}$. This

17 was probably the result of a decrease in the canopy conductance of the RDI trees in

18 response to the increasing evaporative demand and the low soil water content.

19 Regardless, the CWSI of the water-stressed trees is different when calculated at 20 different times of the day, which is not effect of the variation of the NWSB, as this

21 has been already accounted for in Fig. 6. On this specific day, for example, the CWSI 22 could be either 0.6 or 0.8 , depending if $T_{c}$ and $T_{a}$ are measured at $1100 \mathrm{~h}$ or $1500 \mathrm{~h}$, 23 respectively. This finding is in accordance with Jackson et al. (1981), whose analysis

24 lead them to express the CWSI as $1-E_{p} / E_{p m a x}$, where $E_{p}$ is the actual and $E_{p m a x}$ the 25 maximum (unstressed) transpiration. A stressed plant that reduces its stomatal 
1 conductance reduces the ratio $\mathrm{E}_{\mathrm{p}} / \mathrm{E}_{\mathrm{pmax}}$, consequently its CWSI increases. This

2 statement seems equally valid at the time scale of a day: in the morning, the trees $\mathrm{E}_{\mathrm{p}}$

3 was closer to $\mathrm{E}_{\mathrm{pmax}}$ than in the afternoon, and this should happen in plants having

4 enough stomatal control capacity to react significantly to the high evaporative demand

5 of summer afternoons in dry climates.

6 The measurements of midday shaded leaf water potential $(\Psi)$ show the seasonal

7 evolution of the water stress in the two treatments (Fig. 7). While the Control never

8 reached the 1.5 MPa except near harvest, the RDI showed values always between 1.7

9 and $2.5 \mathrm{MPa}$ during the stress timeframe, then approached the $\Psi$ of the Control

10 treatment soon after the full irrigation schedule was restored.

11 The seasonal pattern of the CWSI at $1500 \mathrm{~h}$ for both treatments can be observed in

12 Fig. 8. The CWSI in the RDI trees clearly detects the stress period: the 7-day moving 13 average of CWSI slowly increased as soil water deficits increased during the deficit 14 irrigation period. Also, the CWSI peaks are sharper before irrigations events until the 15 stress period was broken (Fig. 8). Upon the resumption of full irrigation, the CWSI 16 dropped suddenly and remained relatively steady until harvest. The Control, always 17 well irrigated, shows values of CWSI close to zero for the whole season. Certain 18 aspects of the CWSI behaviour should be highlighted. The first is that the CWSI is not 19 entirely stable day-to-day; it shows marked oscillations that are clearly in phase with 20 the irrigation events. Each time an irrigation is applied, the CWSI drops. The 21 reduction in the CWSI after irrigations is more pronounced when the trees are heavily 22 stressed, but this same behaviour can be observed, albeit attenuated, in the Control, 23 with the CWSI always near zero. The amplitude of the oscillations, the quickness of 24 the response after every irrigation, and the absolute values reached at the time of 25 maximum stress are all elements emphasizing the adequacy and the sensitivity of the 
1 CWSI as a stress indicator in pistachio. In fact, comparison of the time-course

2 developments of the CWSI for both treatments suggests that it can be thought of as an

3 "amplified" stress indicator (Fig. 8). Such an extreme sensitivity shown in the RDI

4 trees, with CWSI values reaching $80 \%$ of the maximum potential under moderate

5 water deficits, has not been previously reported for other crop plants in the literature.

6 Whether this behaviour is specific for pistachio is unknown. Also enhancing the 7 sensitivity of the CWSI as a stress indicator was the view angle of the IRT. The leaves

8 which were targeted for measurements were at the very top of the canopy, and they

9 were the most exposed to solar radiation. They also presumably had the lowest

10 boundary layer resistance, being the most ventilated, of all the leaves in the canopy.

11 Thus, they should be under more severe stress than any other sample of leaves in the 12 canopy, including those where the LWP measurements are routinely taken. This 13 suggests that the sensitivity of other remote sensing approaches, such as using aircraft 14 as platforms for thermal imaging, will depend on their ability to assess the Tc of only 15 sunlit leaves, requiring the removal of all other surfaces in the thermal image. In turn, 16 this implies that both thermal and visible Red-Green-Blue images must be used in that 17 the latter can better distinguish between sunlit and mixed pixels. Thus, the smaller the 18 pixel size, the better will be the ability to identify only sunlit pixels and eliminate both 19 soil and shaded leaf pixels. This has implications for the optimal combination of 20 flight height and camera resolution.

21 The second relevant aspect to be pointed out from Fig. 8 is that the RDI recovery after 22 the end of the deficit irrigation schedule, although fast, was not complete. This may be 23 due to either some temporary stress-induced damage to the water transport system 24 (xylem cavitation) or to incomplete restoration of the soil water content throughout 25 the profile, as the irrigation system was probably not able to refill the soil profile in 
1 the deeper layers after the intensive depletion during the stress period. The partial RDI

2 recovery was reflected in the leaf water potential data (Fig. 7).

3 The last important aspect to be noted in Fig. 8 is that there are some days of 4 unreasonably high CWSI, namely DOY 258, 259 and 260. There is no evidence of 5 extreme stress in these periods, as can be seen in Fig. 7, and from the irrigation 6 applied. These high CWSI days are characterised by air temperatures below average 7 and low VPD. Air temperatures were 21, 23 and $25^{\circ} \mathrm{C}$, VPD was $1.7,1.8$ and $2.0 \mathrm{kPa}$ 8 respectively for days 258, 259 and 260: a different atmospheric environment from the 9 period used to derive the baseline (except for wind, that was close to average). Under 10 these conditions, the difference between $\left(T_{c}-T_{a}\right)_{L L}$ and $\left(T_{c}-T_{a}\right)_{U L}$ is very small. Thus, 11 the CWSI is unreliable and the signal-noise ratio of the CWSI is necessarily worse 12 (Jones 2004; Stockle and Dugas 1992). In general, due to the empiricism of the CWSI 13 approach, extreme care must be taken when calculating the CWSI in days when 14 meteorological conditions depart significantly from the average days used to calculate 15 the baselines. For the conditions of this experiment, an unreliable pistachio CWSI 16 may be obtained in days when the VPD was lower than $2 \mathrm{kPa}$ at the time of measurement.

18 There is general agreement that the best current plant-based stress indicator is tree 19 water status since it has been shown to be related to physiological processes (Naor et 20 al. 2006) and crop production (Fereres et al. 2003; Shackel et al. 1997). The best test 21 of the potential utility of other water stress indicators that overcome the logistical 22 limitations of obtaining tree water status is how well they correlate with tree water 23 status. The relationship between CWSI taken at $1500 \mathrm{~h}$ and the midday shaded leaf 24 water potential $(\Psi)$ for the RDI trees is shown in Fig. 9. The coefficient of 25 determination $\left(\mathrm{R}^{2}=0.83\right)$ is higher than what is normally found in literature for other 
1 crops (e.g. Benasher et al. 1992; Sepaskhah and Kashefipour 1994; Wang et al. 2005).

2 The relationship between these two variables can be sometimes misleading: although

3 the leaf water potential is the more widely used index of water stress, its sensitivity,

4 when measured during the day, can be attenuated in fruit trees by the feedback of

5 stomatal closure (Fereres and Goldhamer 1990). In the mild stress range, one may

6 find similar leaf water potentials at midday, with different stomatal conductances and

7 different transpiration rates. On the contrary, the CWSI is theoretically a function of

8 the relative transpiration (Jackson et al. 1981). This may be the reason for the

9 appearance in Fig. 9 of the vertically stretched group of points close to $1.5 \mathrm{MPa}$. In

10 this range of relatively mild stress, the variability in CWSI (the response to the

11 irrigation events even at low CWSI that can be appreciated in Fig. 8) is not reflected 12 in the leaf water potential measurements.

\section{Conclusions}

The temperature of pistachio trees showed great responsiveness to variations in plant water status. The canopy temperature in the stressed trees was considerably higher than in the well-watered ones during most of the day, and irrigation applications

19 reduced the difference.

20 The intercept of the NWSB of pistachio trees changed along the day, while the slope

21 remained constant. The changes in the baseline are mostly explained by the diurnal 22 variations in solar radiation, as evidenced by the relationship found with the zenith 23 solar angle (closely correlated with irradiance in clear sky days).

24 Even when using specific baselines for each time of measurement, the CWSI of 25 pistachio canopies increases significantly during the day if the canopy is 
1 water-stressed, while it is stable in the absence of stress. More stable and sounder

2 values of CWSI, for evaluating the water status for irrigation purposes, are obtained in

3 our experience from $1200 \mathrm{~h}$ to $1500 \mathrm{~h}$, when the CWSI of stressed pistachio canopies

4 reaches its maximum diurnal value.

5 The CWSI measured in the first afternoon hours resulted to be a good descriptor of

6 the seasonal changes in the water status of a pistachio orchard submitted to variable

7 water stress by regulated deficit irrigation. Moreover, it exhibited an extreme

8 sensibility, by responding to irrigations events even when the canopies were under

9 very weak stress conditions. Such responsiveness may be the consequence of 10 targeting the more exposed leaves of the canopy with the infrared thermometers. The

11 viewing angle and the sample of foliage targeted by the IRT devices in our set-up is 12 the same as any remote sensing apparatus (satellite or air-borne), thus we consider the 13 results obtained in this work of great importance for remote sensing studies or 14 applications focused on thermal detection of water stress. This, of course, is only true 15 if the thermal image acquired remotely provides enough resolution to spot only the 16 top of the tree canopies.

\section{Acknowledgements}

21 This work would not have been possible without the assistance of AgriWorld, Inc.,

22 our cooperating grower. They graciously let us use a large block of trees, including

23 installation of equipment and sensors that complicated their farming activities, and 24 never complained. We expressly thank Chris Wylie, ranch supervisor, and Richard 25 Pasley, ranch President. We dedicate this paper to the late Bertrand Gaillard, general 
1 manager, who encouraged and supported our research. We also are grateful for the

2 work of our many field technicians, including Jesus Salinas, Rene Resendez, George

3 Salinas, and Juan Salinas. We appreciate the help of Dr. Elias Fereres in the

4 experimental planning, execution, and data analysis. This work was funded by the

5 California Department of Water Resources, Office of Water Use Efficiency and we

6 thank Peter Brostrom, project manager, for his support and guidance. 


\section{References}

Abduljabbar AS, Lugg DG, Sammis TW, Gay LW (1985) Relationships between Crop Water-Stress Index and Alfalfa Yield and Evapotranspiration. Trans. ASAE 28: 454-461

Andrews PK, Chalmers DJ, Moremong M (1992) Canopy Air-Temperature Differences and Soil-Water as Predictors of Water-Stress of Apple-Trees Grown in a Humid, Temperate Climate. J Am Soc Hortic Sci 117: 453-458

Benasher J, Phene CJ, Kinarti A (1992) Canopy Temperature to Assess Daily Evapotranspiration and Management of High-Frequency Drip Irrigation Systems. Agric Water Manag 22: 379-390

Boland AM, Mitchell PD, Jerie PH, Goodwin I (1993) The Effect of Regulated Deficit Irrigation on Tree Water-Use and Growth of Peach. Journal of Horticultural Science 68: 261-274

Chalmers DJ, Burge G, Jerie PH, Mitchell PD (1986) The Mechanism of Regulation of Bartlett Pear Fruit and Vegetative Growth by Irrigation Withholding and Regulated Deficit Irrigation. Journal of the American Society for Horticultural Science 111: 904-907

Cohen Y, Alchanatis V, Meron M, Saranga Y, Tsipris J (2005) Estimation of leaf water potential by thermal imagery and spatial analysis. Journal of Experimental Botany 56: 1843-1852

Eaton FM, Belden GO (1929) Leaf temperatures of cotton and their relation to transpiration, varietal differences, and yields. U.S.D.A Technical Bulletin n. 91: $1-39$

Ehrler WL (1973) Cotton Leaf Temperatures as Related to Soil-Water Depletion and Meteorological Factors. Agronomy Journal 65: 404-409

Fereres E, Goldhamer DA (1990) Deciduous fruit and nut trees. In: Stewart BA, Nielsen DR (eds) Irrigation of Agricultural Crops, Madison, Wisconsin, pp 987-1017

Fereres E, Goldhamer DA, Parsons LR (2003) Irrigation water management of horticultural crops. Hortscience 38: 1036-1042

Fuchs M (1990) Infrared Measurement of Canopy Temperature and Detection of Plant Water-Stress. Theoretical and Applied Climatology 42: 253-261

Gardner BR, Nielsen DC, Shock CC (1992) Infrared Thermometry and the Crop Water-Stress Index .2. Sampling Procedures and Interpretation. Journal of Production Agriculture 5: 466-475

Garrot DJ, Kilby MW, Fangmeier DD, Husman SH, Ralowicz AE (1993) Production, Growth, and Nut Quality in Pecans under Water-Stress Based on the Crop Water-Stress Index. J Am Soc Hortic Sci 118: 694-698

Gates D (1964) Leaf temperature and transpiration. Agronomy Journal 56: 273-277

Glenn D, Worthington J, Welker W, McFarland M (1989) Estimation of peach tree water use using infrared thermometry. J. Amer. Soc. Hort. Sci 114: 737-741

Goldhamer DA (2005) Tree Water Requirements and Regulated Deficit Irrigation. In: Ferguson L (ed) Pistachio production manual (4th ed.). University of California, Fruit and Nut Research and Information Center, Davis, Ca, USA, pp 103-116 
Goldhamer DA, Beede RH (2004) Regulated deficit irrigation effects on yield, nut quality and water-use efficiency of mature pistachio trees quality and. Journal of Horticultural Science \& Biotechnology 79: 538-545

Goldhamer DA, Fereres E (2001) Simplified tree water status measurements can aid almond irrigation. California Agriculture 55: 32-37

Goldhamer DA, Fereres E, Mata M, Girona J, Cohen M (1999) Sensitivity of continuous and discrete plant and soil water status monitoring in peach trees subjected to deficit irrigation. J Am Soc Hortic Sci 124: 437-444

Hatfield JL, Wanjura DF, Barker GL (1985) Canopy Temperature Response to WaterStress under Partial Canopy. Trans. ASAE 28: 1607-1611

Hipps LE, Asrar G, Kanemasu ET (1985) A Theoretically-Based Normalization of Environmental-Effects on Foliage Temperature. Agric For Meteorol 35: 113122

Hsiao T (1990) Measurements of plant water status. In: Stewart BA, Nielsen DR (eds) Irrigation of agricultural crops. American Society of Agronomy, New York, pp 244-280

Idso SB (1982) Non-Water-Stressed Baselines - a Key to Measuring and Interpreting Plant Water-Stress. Agricultural Meteorology 27: 59-70

Idso SB, Jackson RD, Pinter PJ, Reginato RJ, Hatfield JL (1981) Normalizing the Stress-Degree-Day Parameter for Environmental Variability. Agricultural Meteorology 24: 45-55

Idso SB, Reginato RJ, Clawson KL, Anderson MG (1984) On the Stability of NonWater-Stressed Baselines. Agric For Meteorol 32: 177-182

Jackson RD, Idso SB, Reginato RJ, Pinter PJ (1981) Canopy Temperature as a Crop Water-Stress Indicator. Water Resour. Res. 17: 1133-1138

Jackson RD, Reginato RJ, Idso SB (1977) Wheat Canopy Temperature - Practical Tool for Evaluating Water Requirements. Water Resources Research 13: 651656

Jones HG (1999a) Use of infrared thermometry for estimation of stomatal conductance as a possible aid to irrigation scheduling. Agricultural and Forest Meteorology 95: 139-149

Jones HG (1999b) Use of thermography for quantitative studies of spatial and temporal variation of stomatal conductance over leaf surfaces. Plant Cell and Environment 22: 1043-1055

Jones HG (2004) Irrigation scheduling: advantages and pitfalls of plant-based methods. J Exp Bot 55: 2427-2436

Jones HG, Aikman D, McBurney TA (1997) Improvements to infra-red thermometry for irrigation scheduling in humid climates. Second International Symposium on Irrigation of Horticultural Crops, Vols 1 and 2, pp 259-265

Jones HG, Stoll M, Santos T, de Sousa C, Chaves MM, Grant OM (2002) Use of infrared thermography for monitoring stomatal closure in the field: application to grapevine. Journal of Experimental Botany 53: 2249-2260

Moller M, Alchanatis V, Cohen Y, Meron M, Tsipris J, Naor A, Ostrovsky V, Sprintsin M, Cohen S (2007) Use of thermal and visible imagery for estimating crop water status of irrigated grapevine. Journal of Experimental Botany 58: 827-838

Monteith J, Szeicz G (1962) Radiative temperature in the heat balance of natural surfaces. QJR Meteorol. Soc 88: 496-507 
Moran MS, Clarke TR, Inoue Y, Vidal A (1994) Estimating Crop Water-Deficit Using the Relation between Surface-Air Temperature and Spectral Vegetation Index. Remote Sensing of Environment 49: 246-263

Nakayama FS, Bucks DA (1983) Application of a Foliage Temperature Based Crop Water-Stress Index to Guayule. J Arid Environ 6: 269-276

Naor A, Gal Y, Peres M (2006) The inherent variability of water stress indicators in apple, nectarine and pear orchards, and the validity of a leaf-selection procedure for water potential measurements. Irrigation Science 24: 129-135

Nielsen DC (1994) Non-Water-Stressed Base-Lines for Sunflowers. Agric Water Manag 26: 265-276

Qiu G, Momii K, Yano T (1996) Estimation of plant transpiration by imitation leaf temperature. I. Theoretical consideration and field verification. Trans. Jpn. Soc. Irrig., Drain. Reclam. Eng 64: 401-410

Sepaskhah AR, Kashefipour SM (1994) Relationships between Leaf Water Potential, Cwsi, Yield and Fruit-Quality of Sweet Lime under Drip Irrigation. Agric Water Manag 25: 13-22

Sepulcre-Canto G, Zarco-Tejada PJ, Jimenez-Munoz JC, Sobrino JA, de Miguel E, Villalobos FJ (2006) Detection of water stress in an olive orchard with thermal remote sensing imagery. Agric For Meteorol 136: 31-44

Shackel K, Ahmadi H, Biasi W, Buchner R, Goldhamer D, Gurusinghe S, Hasey J, Kester D, Krueger B, Lampinen B (1997) Plant water status as an index of irrigation need in deciduous fruit trees. HortTechnology 7: 23-29

Stockle CO, Dugas WA (1992) Evaluating Canopy Temperature-Based Indexes for Irrigation Scheduling. Irrig Sci 13: 31-37

Tanner CB (1963) Plant Temperatures. Agron J 55: 210-\&

Tormann, H (1986) Canopy temperature as a plant water stress indicator for nectarines. South African journal of plant and soil 3: 110-114

Turner NC, Long MJ (1980) Errors Arising from Rapid Water-Loss in the Measurement of Leaf Water Potential by the Pressure Chamber Technique. Aust J Plant Physiol 7: 527-537

Wallace R, Clum H (1938) Leaf Temperatures. American Journal of Botany 25: 83-97

Wang LM, Qiu GY, Zhang XY, Chen SY (2005) Application of a new method to evaluate crop water stress index. Irrig Sci 24: 49-54

Wanjura DF, Hatfield JL, Upchurch DR (1990) Crop Water-Stress Index Relationships with Crop Productivity. Irrigation Science 11: 93-99

Wanjura DF, Kelly CA, Wendt CW, Hatfield JL (1984) Canopy Temperature and Water-Stress of Cotton Crops with Complete and Partial Ground Cover. Irrig Sci 5: 37-46

Yazar A, Howell TA, Dusek DA, Copeland KS (1999) Evaluation of crop water stress index for LEPA irrigated corn. Irrig Sci 18: 171-180 
Tables

Table 1

Kc values adopted for scheduling the irrigations in this experiment (from Goldhamer 2005).

\begin{tabular}{ll}
\hline Period & $\mathbf{K}_{\mathbf{c}}$ \\
\hline 1-15 Apr & 0.07 \\
16-30 Apr & 0.43 \\
1-15 May & 0.68 \\
16-31 May & 0.93 \\
1-15 Jun & 1.09 \\
16-30 Jun & 1.17 \\
1-15 Jul & 1.19 \\
16-31 Jul & 1.19 \\
1-15 Aug & 1.19 \\
16-31 Aug & 1.12 \\
1-15 Sep & 0.99 \\
16-30 Sep & 0.87 \\
1-15 Oct & 0.67 \\
16-31 Oct & 0.50 \\
1-15 Nov & 0.35 \\
\hline
\end{tabular}


Table 2

Parameters of the non-water-stressed baseline $(a+b$-VPD) at different time of the day presented in Fig. 3. Also given are the parameters for the baseline obtained from all the measurements taken from 1200 to $1500 \mathrm{~h}$. Data obtained from all available days in the well-irrigated Control plot.

\begin{tabular}{cccc}
\hline hour & Intercept $(a)$ & Slope $(b)$ & $\mathrm{R}^{2}$ \\
\hline 0800 & 0.28 & -1.55 & 0.77 \\
0900 & 1.27 & -1.68 & 0.88 \\
1000 & 1.74 & -1.50 & 0.88 \\
1100 & 2.35 & -1.46 & 0.89 \\
1200 & 2.50 & -1.36 & 0.89 \\
1300 & 2.49 & -1.29 & 0.86 \\
1400 & 2.46 & -1.30 & 0.87 \\
1500 & 2.00 & -1.30 & 0.88 \\
1600 & 0.97 & -1.25 & 0.85 \\
1700 & 0.48 & -1.19 & 0.75 \\
\hline 1200 to 1500 & 2.44 & -1.33 & 0.87 \\
\hline
\end{tabular}




\section{List of figures}

Fig. 1

Mounting position of the infra-red thermometers over the trees.

Fig. 2

Examples of diurnal courses of the canopy temperature $\left(T_{c}\right.$, left side, plots a-b-c) and canopy-air differential $\left(T_{c}-T_{a}\right.$, right side, plots d-e-f). Plots a and d: DOY 169 (18 June), during the deficit irrigation timeframe for the RDI treatment, after 10 days from the last RDI irrigation. Plots b and e: DOY 170 (19 June), during and after an irrigation, but RDI still deficit irrigated. Plots c and f: DOY 227 (15 August), 34 days after the RDI irrigation scheduling was switched to optimum water requirements.

\section{Fig. 3}

Changes in the non-water-stressed baseline of a mature pistachio orchard along the day. The slope of the baselines (obtained by regressing $T_{c}-T_{a}$ of the well watered crop versus VPD) is almost always the same, while the intercept noticeably moves upward in the morning (a) and downward in the afternoon (b). The bold dashed line in $b$ is the non-water-stressed baseline obtained using data from 1200h to 1500h. Data obtained from all available days in the well-irrigated Control plot.

Fig. 4

Relation between the intercept of the non-water-stressed baseline and the zenith solar angle in clear-sky days. 


\section{Fig. 5}

Non-water stressed baselines at $1500 \mathrm{~h}$ in different classes of wind speed. The average wind speeds for the three classes are: $2.1,3.0$ and $4.1 \mathrm{~ms}^{-1}$. Data obtained from all available days in the well-irrigated Control plot.

\section{Fig. 6}

Diurnal evolution of CWSI in the Control (black dots) and RDI (black squares) on 3 July 2006 (DOY 184). The values are calculated with 10min average canopy and air temperatures measurements and by varying the NWSB as described in Fig. 3 and Table 2. The bold lines are 5-periods moving averages. Also shown is the midday shaded leaf water potential $(\Psi$, white circles $=$ Control, white squares $=$ RDI).

\section{Fig. 7}

Seasonal evolution of midday shaded leaf water potential $(\Psi)$ in the Control (black dots) and RDI (white squares) treatments. The length of the error bars is the standard deviation. The vertical dotted line marks the end of the RDI stress timeframe.

\section{Fig. 8}

Seasonal evolution of CWSI in Control (black dots, dashed thin line) and RDI (white squares, solid thin line), obtained by air and canopy temperatures measurements at 1500h. The bold lines (dashed for the Control and solid for the RDI) are the 7-day moving averages. The arrows indicate the days of irrigation in the two treatments: upward arrows in the Control and downward arrows in the RDI. 
Fig. 9

Relation between the mid-day shaded leaf water potential ( $\Psi)$ and the CWSI at $1500 \mathrm{~h}$ measured during the season in the RDI treatment. The error bars are twice the standard deviation. 
Figures

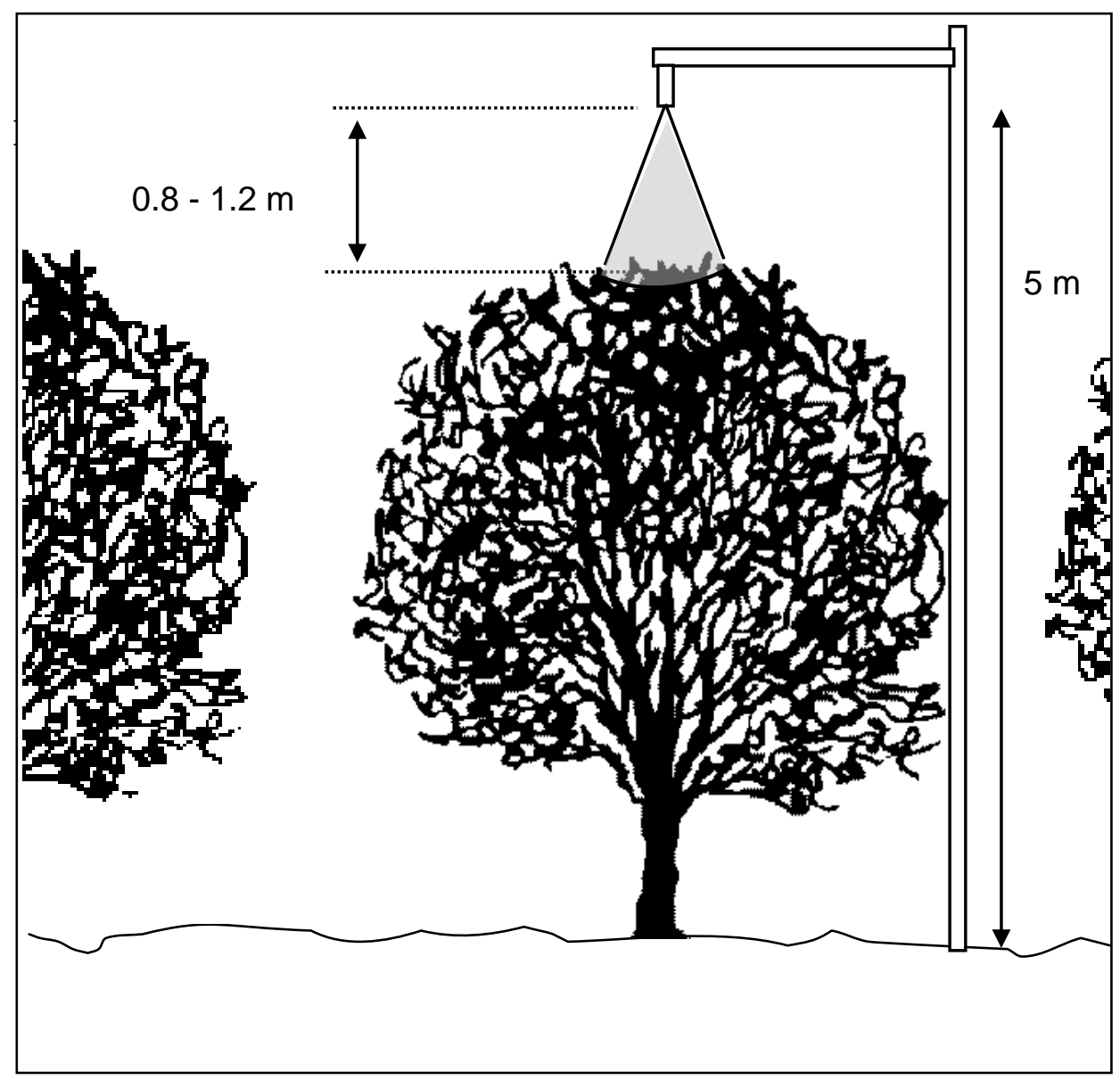




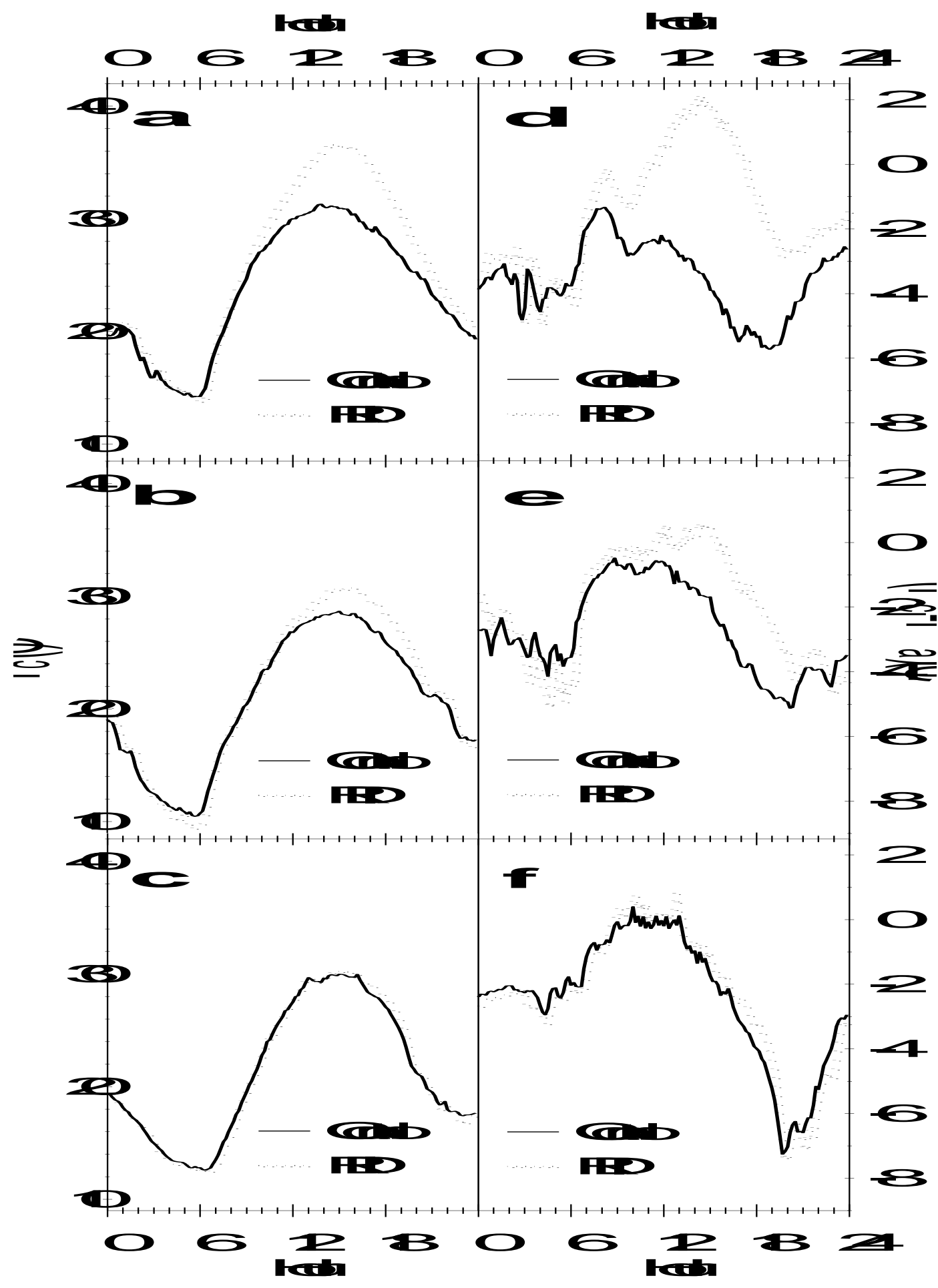

Fig. 2 


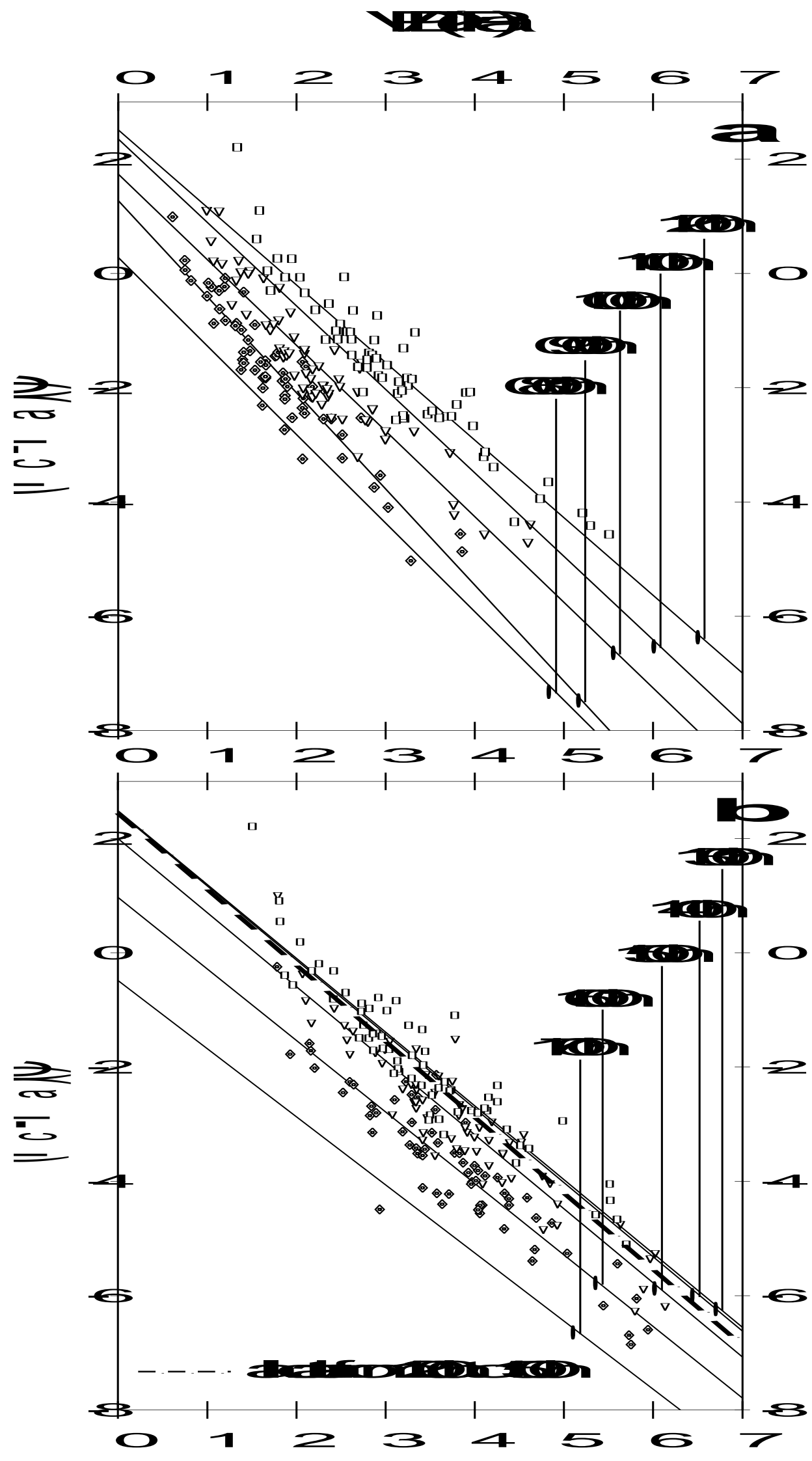

Fig. 3 


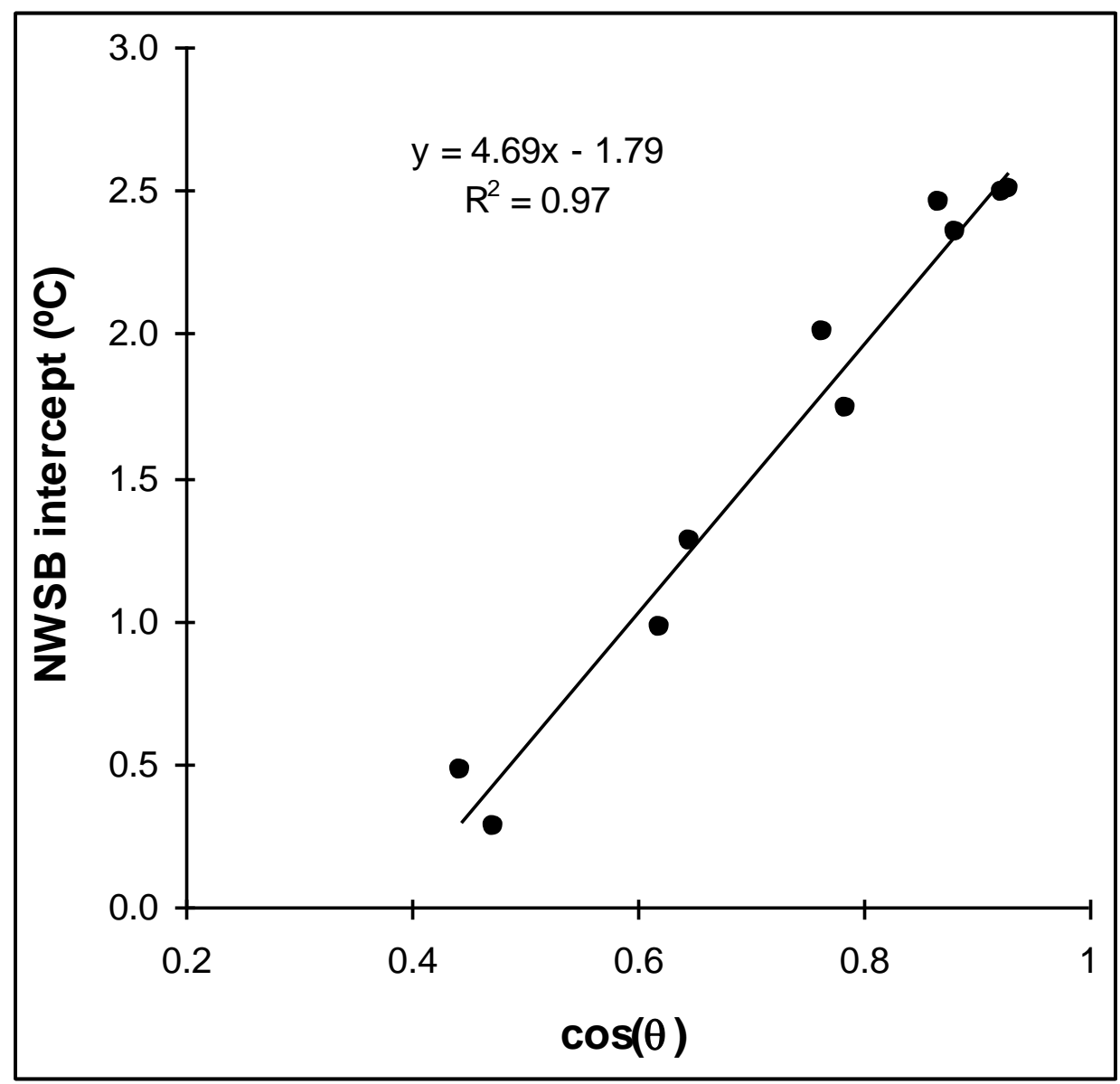

Fig. 4 


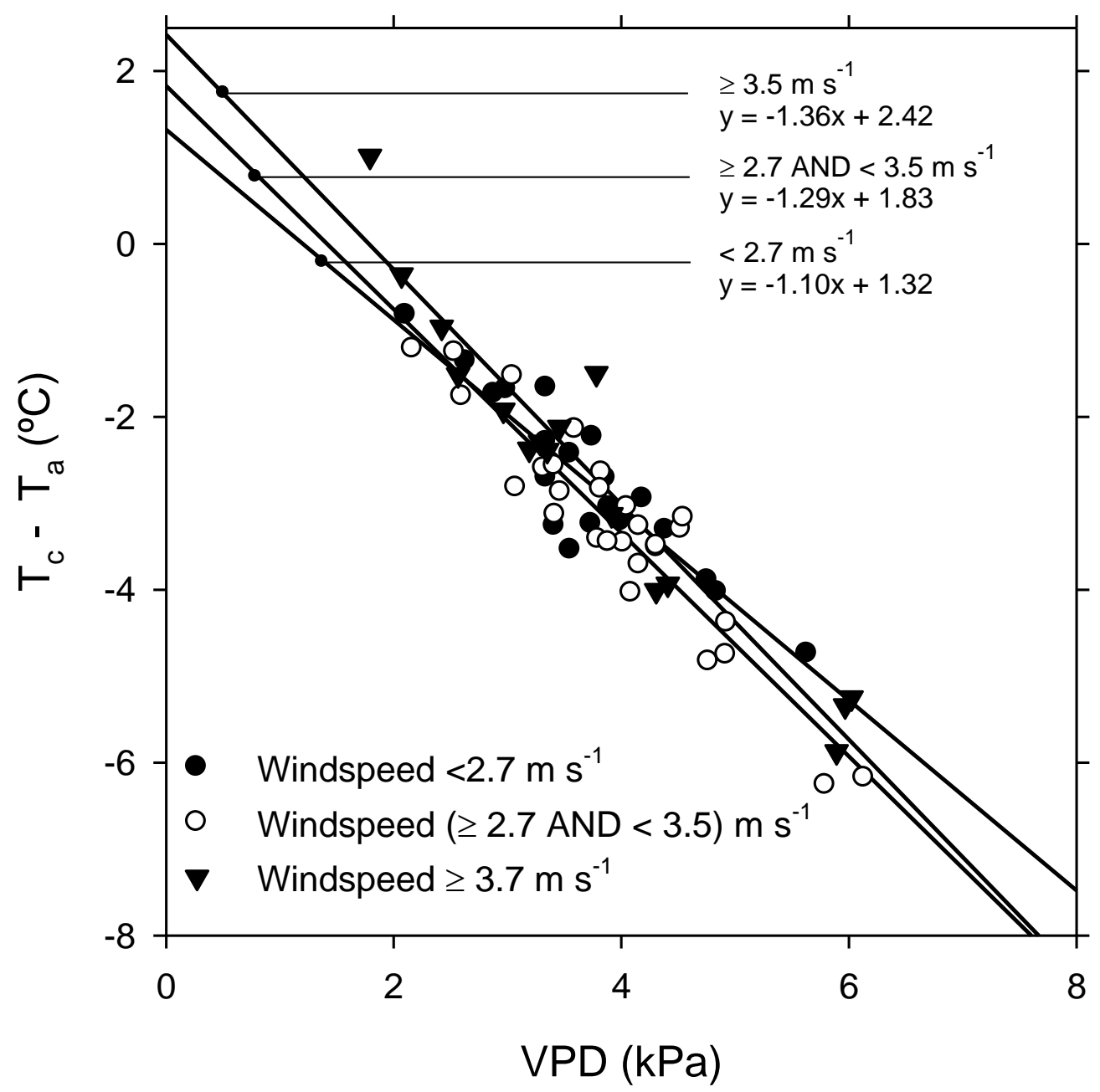

Fig. 5 


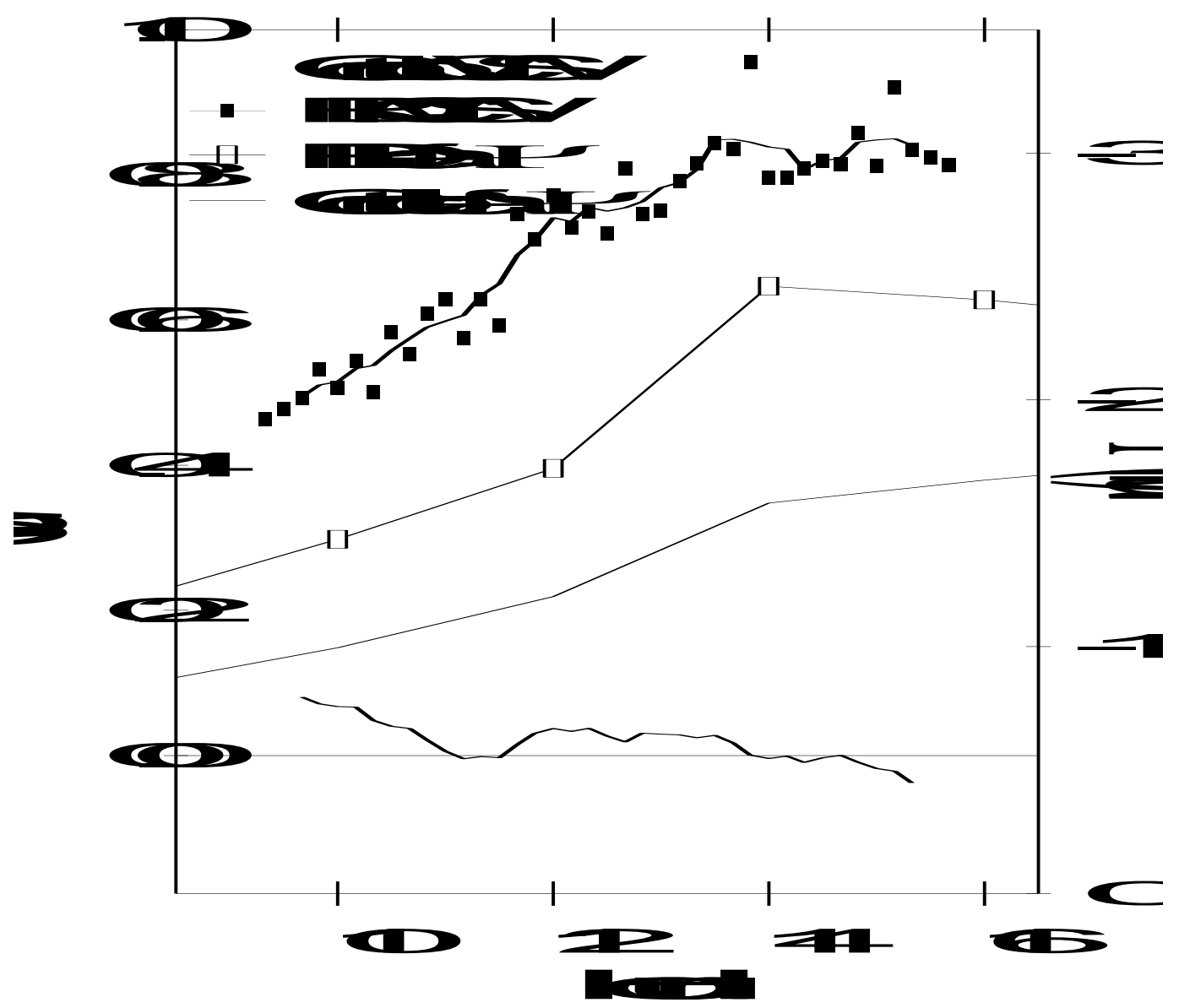

Fig. 6 


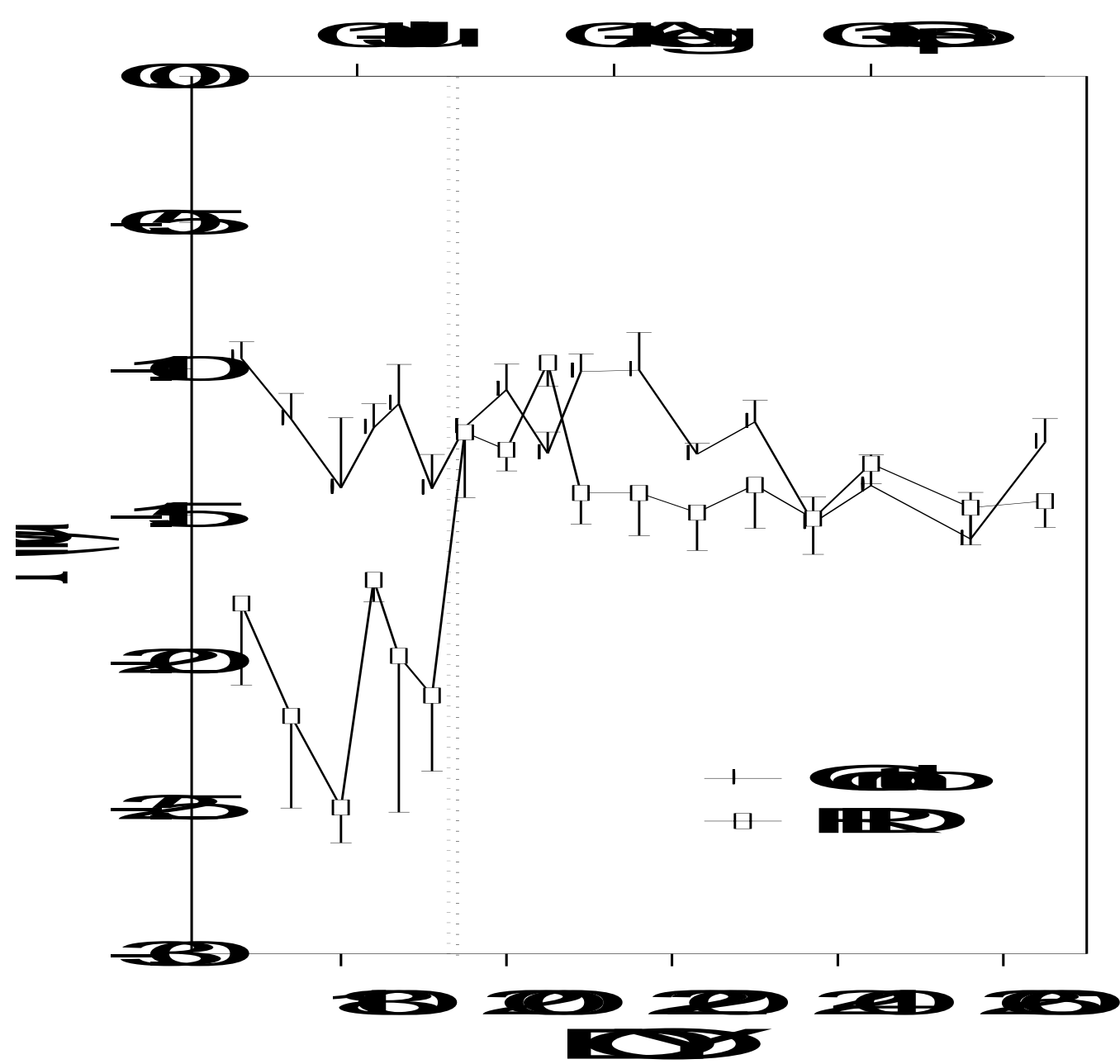

Fig. 7 


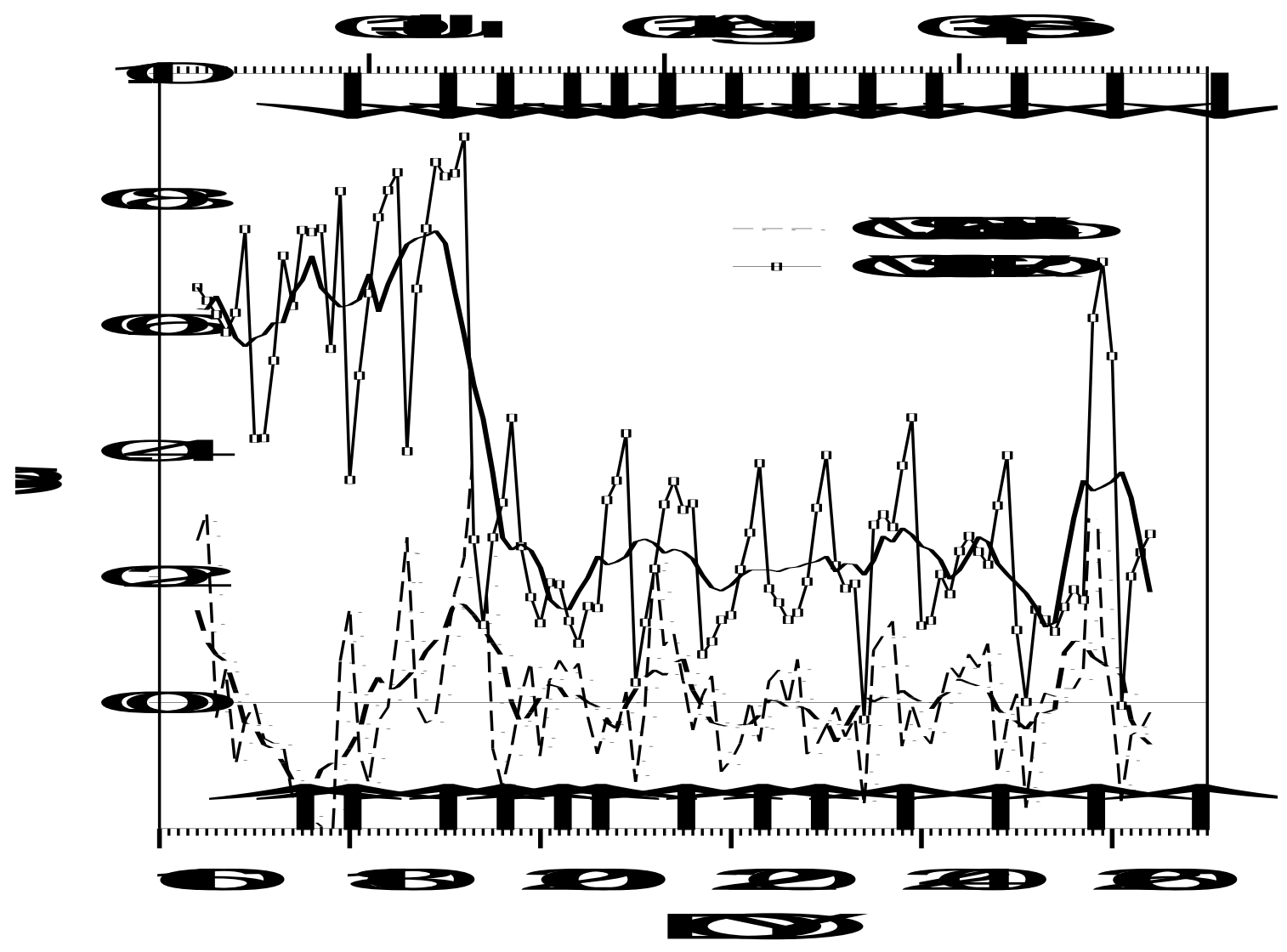

Fig. 8 


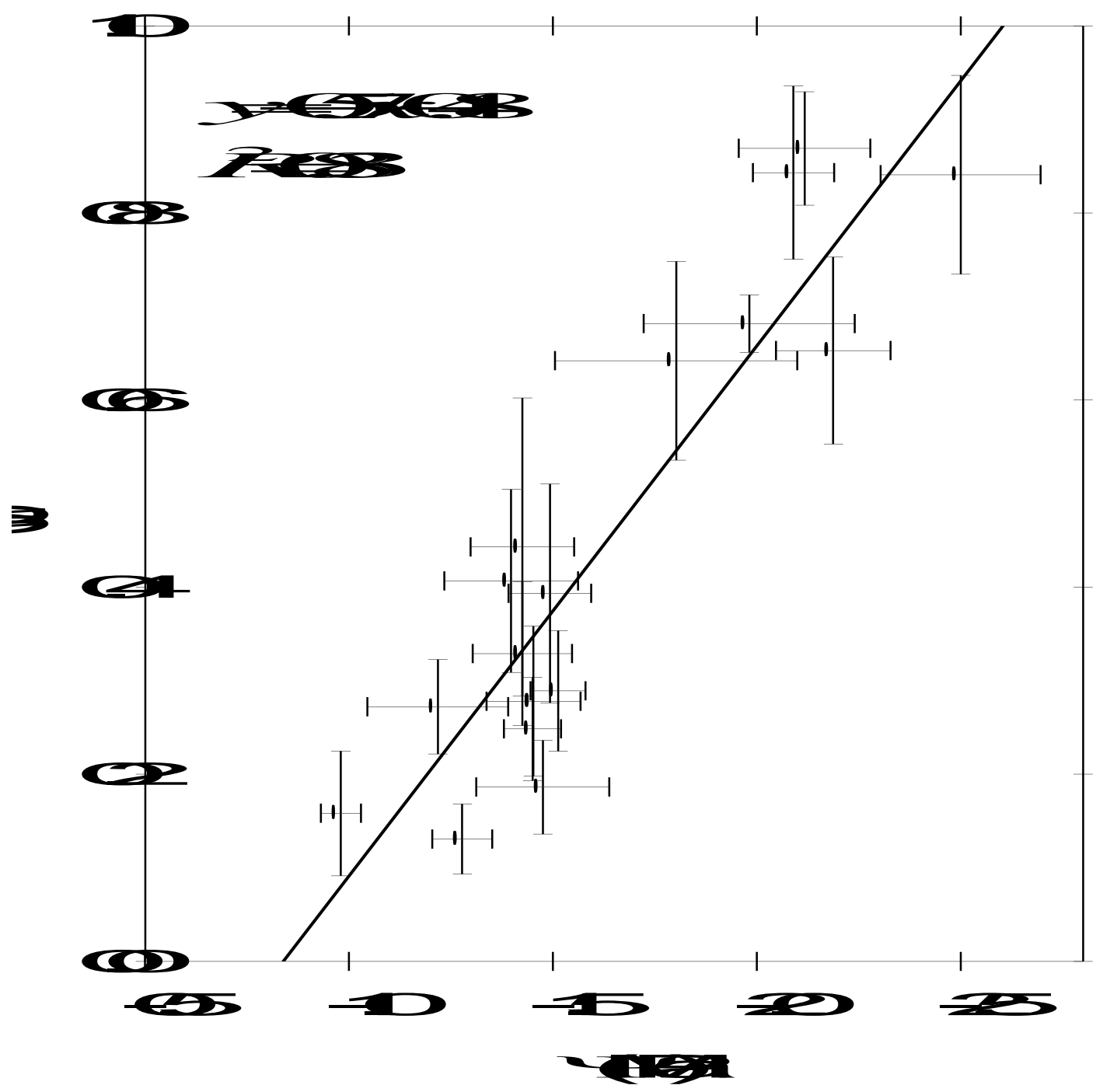

Fig. 9 